\title{
PRÁTICAS EDUCATIVAS: OPINIÃO DE DISCENTES DE UMA INSTITUIÇÃO FEDERAL DE ENSINO SUPERIOR
}

\author{
Maria Clara Soares Dantas \\ UFCG \\ dantasclarinha@gmail.com
}

Ana Cláudia de Queiroz

UFCG

claudia.ana.queiroz@gmail.com

\author{
Roberta Karlla Oliveira Guedes \\ UFCG \\ rkog92@gmail.com
}

Luciana Dantas Farias de Andrade

UFCG

luciana.dantas.farias@gmail.com

RESUMO: Objetivo: conhecer a opinião de discentes de uma Instituição Federal de Ensino Superior acerca das práticas educativas que ancoram os processos de ensino e avaliação em uma Universidade Federal do interior da Paraíba-PB-Brasil. Metodologia: Estudo de natureza predominantemente qualitativa ancorado no prisma metodológico do materialismo histórico dialético foi possível emergir as contradições das atividades docentes a partir das entrevistas virtuais realizadas com 14 estudantes dos cursos de bacharelado em Física, Química, Matemática, Biologia, Enfermagem, Nutrição e Farmácia no período de junho, julho e agosto de 2020. Resultados: os temas principais oriundos das falas dos entrevistados permitiram a depreensão de duas categorias empíricas: I- Aspectos potencializadores das práticas educativas; II- Aspectos limitadores das práticas educativas. Ficou evidente a escolha por diversas estratégias pedagógicas nas atividades laborais dos professores da saúde e educação. Conclusão: essa diversidade convergiu para uso de abordagens pedagógicas emancipatórias e não emancipatórias, na opinião dos entrevistados, demonstrando avanço pedagógico diante da possibilidade de reconsiderar as ações docentes em vistas à superação de metodologias tradicionais através da operacionalização dos pressupostos da Resolução Nacional que institui as Diretrizes Curriculares dos Cursos.

Palavras-chave: Educação. Pessoal de educação. Mercado de trabalho. 


\section{ABSTRACT \\ EDUCATIONAL PRACTICES: OPINION OF STUDENTS OF A FEDERAL HIGHER EDUCATION INSTITUTION}

Objective: to know the opinion of students of a Federal Institution of Higher Education about the educational practices that anchor the teaching and assessment processes in a Federal University of the Interior of Paraíba-PB-Brazil. Methodology: Predominantly qualitative study anchored in the methodological prism of dialectical historical materialism, it was possible to emerge as contradictions of teaching activities from virtual sources carried out with 14 students of bachelor's degrees in Physics, Chemistry, Mathematics, Biology, Nursing, Nutrition and Pharmacy in the period of June, July and August 2020. Results: the main themes arising from the interviewees' statements allowed the understanding of two empirical categories: IPotentializing aspects of educational practices; II- Limiting aspects of educational practices. The choice of pedagogical subjects in the work activities of health and education teachers was evident. Conclusion: this diversity converged to the use of emancipatory and nonemancipatory pedagogical approaches, in the opinion of the interviewees, demonstrating pedagogical progress in view of the possibility of reconsidering teaching actions with a view to overcoming previous methodologies through the operationalization of the assumptions of the National Resolution establishing the guidelines Course Curriculum.

Keywords: Education. Educational Personnel. Job market. 


\section{INTRODUÇÃO}

A presente investigação está vinculada ao Grupo de Estudos e Pesquisas Interdisciplinares em Saúde e Enfermagem (GEPISE) e é fruto de inquietações em face da importância das discussões envolvendo a formação acadêmica de estudantes universitários de uma Instituição de Ensino Superior do interior do nordeste brasileiro, devido à atuação docente e discente das pesquisadoras em observar o interesse dos estudantes para aspectos tecnicistas em detrimento aos componentes curriculares epistemológicos voltados à reflexão e aprofundamento acadêmico.

As discussões reflexivas no contexto dos grupos de pesquisa promovem a formação de novos pesquisadores, produz conhecimentos avançados com necessidade de infraestrutura física, pessoal, organizativa e logística. Considera que a prática da produção de conhecimentos é um processo coletivo, dinâmico, contínuo e complementar, além de integrar tecnologias da informação e comunicação na produção, consumo e disseminação do conhecimento, por esta razão, faz-se alusão às discussões no âmbito do GEPISE e sua importância para a construção de uma proposta que reflita a importância da formação acadêmica no âmbito da universidade (ERDMANN et al, 2013; FIOCHI, 2016).

No planejamento do ensino, os objetivos específicos antecipam resultados e processos esperados do trabalho conjunto do professor e dos alunos, expressando conhecimentos e habilidades (conteúdos programáticos) a serem assimilados de acordo com as exigências metodológicas (estratégias com procedimentos e recursos) para finalmente sofrerem a avaliação sobre sua validade. (FARIAS; SILVA, 2008)

A elaboração das práticas educativas envolvendo o ensino e avaliação para a formação de recursos humanos acarreta para os professores da graduação/bacharelado a necessidade de optar por uma, entre duas posições: limitar-se ao repasse de conhecimentos já consagrados, investindo no desenvolvimento de algumas capacidades muito gerais, fora de qualquer referência a situações e práticas sociais, aqui denominados de Planejamento de Ensino Não Emancipatório, ou podem assumir toda a responsabilidade na escolha das práticas sociais optando por referenciais teóricos - práticos, com enfoque em questões que podem ser problematizadas tanto no plano individual como no coletivo, potencialmente para a formação de um perfil profissional que atenda às necessidades da política de saúde vigente, o qual denominou de Planejamento de Ensino Emancipatório (LIBÂNEO, 2005). 
Nesse sentido, os processos de ensino precisam apresentar-se com potencial transformador, sobretudo depois do advento do Plano Nacional de Educação - PNE, que instituiu as Diretrizes Curriculares Nacionais. Isso significa que o novo enfoque requer igualmente novas tendências técnico-pedagógicas, além de alterações nas estratégias de ensino no âmbito do processo formativo.

Mediante a possibilidade de realização das novas tendências teórico-pedagógicas das práticas educativas em enfermagem e das consequentes alterações nas estratégias de ensino e avaliação do processo formativo, questiona-se: qual a opinião dos discentes dos cursos do Centro de Educação e Saúde de uma Instituição Federal de Ensino Superior acerca das práticas educativas?

Este estudo tem como objetivo geral conhecer a opinião de discentes de uma Instituição Federal de Ensino Superior acerca das práticas educativas que ancoram os processos de ensino e avaliação em uma Universidade Federal do interior da Paraíba-PBBrasil. Como objetivos específicos: 1. Caracterizar o perfil sociodemográfico dos estudantes do CES; 2. Elucidar as transformações históricas da formação acadêmica no âmbito da universidade; 3. Conhecer as contradições existentes na opinião de discentes.

Justifica-se a sua realização face à constatação de que o ensino das disciplinas experimentam, nos dias atuais, a possibilidade de implementação de novas tendências teórico-pedagógicas, com alterações nas suas estratégias de ensino, devido ao advento das Diretrizes Curriculares que proporcionou às Universidades o direito de definir as estruturas curriculares de seus cursos, explicitando as competências e habilidades que desejam desenvolver junto a seus alunos, a partir de um Projeto Político Pedagógico capaz de atender às necessidades educacionais em âmbito local.

\section{MÉTODOS}

Este trabalho utiliza o prisma teórico metodológico do materialismo histórico dialético que, dentre outros princípios, trabalha a contradição por entender que para pensar a realidade é preciso elucidar os extremos para se aproximar do essencial, ou seja, partindo do empírico, do real aparente, avançando para reflexões, teorias e abstrações faz-se possível o acesso à essência daquela realidade tendo leituras diretas alimentadas por feedbacks (MINAYO, 2007; COSTA; LOUREIRO, 2019). 
O estudo do tipo exploratório-descritivo, foi desenvolvido a partir da abordagem qualitativa. O cenário consistiu no contexto dos cursos oferecidos no Centro de Educação e Saúde (CES) de um campus em expansão da Universidade Federal de Campina Grande respeitando os trâmites do comitê de ética (Resolução 466/12 conforme apêndice B), necessários à viabilização de uma pesquisa envolvendo seres humanos, com estimativa para o início do trabalho de campo compreendido entre os meses de novembro, dezembro de 2019, janeiro e fevereiro de 2020.

Contudo, devido ao atraso na emissão do parecer do Comitê de Ética para dezembro de 2020, férias acadêmicas em janeiro e fevereiro/2020 o cronograma foi alterado para início da coleta de material empírico para março de 2020. Infelizmente, em março de 2020, quando entrou em contato com os alunos para agendar a entrevista presencial, a UFCG emitiu nota informativa orientando professores e alunos da necessidade de isolamento social em decorrência da pandemia do novo Coronavírus.

Diante do novo cenário de isolamento social, as entrevistas tiveram que ser adaptadas e foram realizadas de maneira virtual através da plataforma Google Meet nos meses de junho, julho e agosto de 2020. A população foi constituída por estudantes dos cursos oferecidos no CES: Cursos de Bacharelado em Física, Química, Matemática, Biologia, Enfermagem, Nutrição e Farmácia. A amostra foi composta por 14 estudantes que convergiram com os critérios de inclusão, não desistiram do estudo em nenhuma das etapas realizadas até a saturação teórica por exaustão, ou seja, quando a interação entre o campo de pesquisa e o investigador não mais fornece elementos para balizar a teorização do objeto de estudo (FONTANELLA et al, 2011; SILVA; RUSSO, 2019).

Foram adotados os seguintes critérios de inclusão para realização da pesquisa com os estudantes: i) estudantes com idade superior a 18 anos; ii) estudantes regularmente matriculados no sistema de informação da Instituição de Ensino Superior. Com relação aos critérios de exclusão, foram respeitados os seguintes: i) acadêmicos que não estavam cadastrados no sistema de informação da Universidade; ii) interferências acadêmicas, religiosas, culturais ou qualquer natureza que interferisse na lisura da pesquisa. Apenas dois alunos não quiseram participar da pesquisa, não expuseram o motivo e a decisão foi respeitada. 
Entende-se como fatores de risco nesta pesquisa: constrangimento, estresse emocional, omissão de respostas relacionadas aos sentimentos de intimidação pela entrevista. Mesmo não tendo benefícios diretos aos sujeitos da pesquisa por participarem deste estudo, indiretamente fortalece a compreensão do fenômeno estudado e estimula a produção do conhecimento científico.

Para auxiliar o desenvolvimento da investigação foi utilizada entrevista com uso de roteiro semiestruturado, pois valorizou a presença virtual do investigador e ofereceu as perspectivas possíveis para que o informante tivesse liberdade e espontaneidade necessárias a uma investigação de enfoque qualitativo. Essa técnica parte de certos questionamentos básicos, permitindo ao informante a liberdade para seguir a linha de seu pensamento e de suas experiências dentro do foco principal colocado pelo investigador. (TRIVIÑOS, 2001; SILVA; RUSSO, 2019).

Após a assinatura do Termo de Consentimento Livre e Esclarecido (TCLE), no qual o entrevistado tinha acesso por e-mail, assinava, digitaliza e enviava ao pesquisador ficando com a via original, foram realizadas as entrevistas utilizando a gravação do áudio com duração em média de 9 minutos, sendo feitas em horários marcados em combinação com o entrevistado através da plataforma Google Meet com a transcrição na íntegra no mesmo dia, juntamente com a organização dos dados sociodemográficos.

Para assegurar o sigilo das informações, os depoentes foram numerados do "1" ao "14", conforme a sequência das entrevistas, e identificados pela letra "E".

A partir das transcrições na íntegra foi feita a depreensão dos temas principais que foram organizados e agrupados em blocos de significação, em que foi possível codificar os fragmentos das falas dos estudantes, dado bruto extraído, em unidades de representação daquilo que descreviam acerca das práticas educativas dos professores de uma Instituição Federal de Ensino Superior. Após leituras e releituras do dado bruto foi possível, pela técnica de análise de discurso de Fiorin, a compreensão das opiniões discentes expressas pelos estudantes por meio das categorias empíricas (FIORIN, 2005).

\section{RESULTADOS}


Descrição da caracterização do perfil sociodemográfico dos estudantes e apresentação dos elementos oriundos das transcrições de suas falas, contemplando, desta maneira, a amostra empírica de (5) graduandos de cursos da área da saúde, sendo (3) do curso de enfermagem, (1) da nutrição e (1) da farmácia; e (9) graduandos de cursos da área da educação, sendo (3) de ciências biológicas, (2) da química, (2) da física e (2) da matemática. Todos os graduandos eram alunos da Instituição Federal de Ensino Superior, portanto, viabilizando o confronto com o embasamento teórico da literatura pertinente.

Os dados coletados permitiram conhecer os aspectos sociodemográficos dos estudantes levando em consideração seus dados pessoais e acadêmicos. Compreendendo que a formação acadêmica é um pilar primordial para a construção e estruturação de um senso crítico, foi questionado aos entrevistados se estes já haviam tido contato ou formação em outro curso, tendo assim um predomínio de 93\% que não possuía outra formação enquanto $7 \%$ relatou formação técnica.

No que se refere ao estado civil, em torno de $93 \%$ afirmaram ser solteiros e $7 \%$ casados, apresentando um perfil acadêmico jovem com expectativas para contribuição social em curto, médio e longo prazo. Dos 14 entrevistados, 05 (36\%) cursam na área da saúde e $100 \%$ são do sexo feminino. Já os outros 09 participantes (64\%) cursam na área da educação sendo 04 (44\%) do sexo masculino e 05 (56\%) do sexo feminino. Desta forma, houve predomínio do sexo feminino nesta pesquisa.

A partir dos depoimentos, e baseado na técnica de análise de discurso, foi possível emergir duas categorias empíricas: I- Aspectos potencializadores das práticas educativas; IIAspectos limitadores das práticas educativas.

\subsection{Aspectos potencializadores das Práticas Educativas}

No tocante à análise dos depoimentos dos entrevistados foi possível observar o relato das práticas educativas que ancoram os processos de ensino e avaliação realizados pelos docentes que ministram aulas no Centro de Educação e Saúde (CES), sendo possível observar aspectos potencializadores nos depoimentos expostos:

Têm umas formas de avaliação em algumas disciplinas, principalmente as disciplinas pedagógicas da gente, então que eu acho muito interessante que as professoras, elas estimulam muito a gente a pensar, a desenvolver a nossa criatividade, o nosso senso crítico inclusive a pensar em novos métodos de avaliação pra gente usar na nossa profissão, elas usam muito a questão do debate na sala de aula, da 
participação do aluno e eu acho muito interessante essa questão, esse ponto de avaliação, principalmente o debate por que no debate é onde você pode perceber o que o aluno entende sobre aquele assunto, então fica bem melhor do que uma prova escrita. (Linha 123 a 137) E5 - estudante de um curso da área da educação

Muita gente não gosta, mas eu gosto de seminário, eu gosto de mapas mentais, ajuda bastante e alguns professores utilizaram, fizeram uso desse método. Investigação, assim, um estudo mais por investigação, o professor dá um determinado tema e faz com que a gente busque isso, faça uma investigação e eu gosto muito de artigo, quando os professores passam artigo para ser debatido em sala de aula e eu gosto também quando eles colocam vídeos, assim, pequenos, mas que são bem didáticos. (Linha 49 a 60) E7- estudante de um curso da área da educação

Na sala de aula a gente ter oportunidade de participar ativamente das aulas e fazer discussão e sempre as aulas parecerem que estão acontecendo, que tá rolando uma conversa e não ficar pesado. (Linha 52 a 56) E9 - estudante de um curso da área da saúde

Os professores são muito didáticos, a maioria, né? Como a gente tem muitas horas de aula, às vezes duas aulas seguidas, dá pra ver a teoria bem direitinho. (Linha 32 a

35) E3- estudante de um curso da área da saúde

\section{Aspectos limitadores das Práticas Educativas}

Quando os entrevistados foram questionados quanto aos aspectos limitadores das práticas educativas que ancoram os processos de ensino e avaliação utilizados pelos docentes que ministram aulas no Centro de Educação e Saúde (CES), foi possível visualizar a opinião dos estudantes nos trechos abaixo:

... por que aquele negócio de aula, só prova com passar o conteúdo e prova, eu acho que não tem muito aprendizado (Linha 44 a 46) E2 - estudante de um curso da área da saúde

Eu acho que precisava ter mais aula prática, acho que deixa um pouco a desejar nisso de ter pouca aula prática. (Linha 2 a 5) E3 - estudante de um curso da área da saúde

... porém na universidade eu sinto muito ainda aquele ensino tradicional por parte de alguns professores, aquele ensino onde o professor chega joga aquele conteúdo ali no quadro e explica e a gente, se não absorver ali, tem que meio que se virar sozinho. (Linha 48 a 54) E5 - estudante de um curso da área da educação

A avaliação em si não se dá, se dá pelo professor, né? Que, às vezes, a gente vai ter que fazer a prova, infelizmente a gente tem que fazer essa prova escrita, mas os professores geralmente dessa área abusam, né? Das provas. Por que não sabem outros métodos de avaliação, podem ser usados outros métodos de avaliação, né? Infelizmente, vai ter a prova, mas pode se usar as outras notas para fazer outras avaliações abertas que não sejam exatamente a prova. (Linha 45 a 55) E11 estudante de um curso da área da educação 


\section{DISCUSSÃO}

Aspectos potencializadores das Práticas Educativas

Pelos relatos, os professores utilizam diversas estratégias pedagógicas em suas práticas educativas: estímulo no pensamento crítico e reflexivo, debates, seminários, mapas mentais, investigação, discussão de artigos científicos e exposição de vídeos.

Entendendo que seja um aspecto potencializador das práticas educativas, não se pode assegurar se esses acadêmicos têm conhecimento dos tipos de práticas educativas e seus aspectos positivos e negativos. No entanto, seus relatos expressam admiração na escolha pedagógica dos professores quanto à diversidade de estratégias que têm utilizado no tocante ao ensino.

Parte-se do princípio que as práticas educativas que ancoram os processos de ensino e avaliação envolvem aspectos de cunho ideológico, ou seja, a atuação docente apresenta-se isenta de parcialidade e parte da triangulação do aprendizado do discente: a efetivação da ação educativa dos professores, o conteúdo programático e o espaço de tempo determinando (VIEIRA et al, 2020).

Essa triangulação do aprendizado pode ser apontada nas falas de E9 e E5, ao enfatizarem a participação ativa do aluno no ambiente acadêmico, principal característica das abordagens pedagógicas emancipatórias: “... a gente ter oportunidade de participar ativamente das aulas e fazer discussão" (E9), "... da participação do aluno" (E5). O diálogo entre professor e aluno assume o seu papel emancipatório por meio da relação horizontal, visando empatia, troca e respeito mútuo, entendido como aspecto potencializador das atividades laborais dos professores da Instituição de Ensino Superior pesquisada (VIEIRA et al, 2020).

Aspectos limitadores das Práticas Educativas

Diante da concepção empirista, o aluno é visto como ser passivo, desta forma, nele é depositada as informações e conhecimentos que, na teoria freiriana, é denominada de "educação bancária". Dispondo de atividades centradas unicamente no professor para a condução do processo ensino-aprendizagem e solicitação da reprodução desse 
conhecimento, ou seja, dependente unicamente do potencial cognitivo para efetivação da aprendizagem, pode-se afirmar a aproximação com a educação bancária, postulada por Paulo Freire, em professores da área da educação e saúde. (RUIZ-MORENO; PITTAMIGLIO; FURUSATO, 2008; ANDRADE et al, 2018).

Os métodos de avaliação tradicionais aspiram à fiel reprodução do conteúdo passado em sala de aula e devem ser armazenados pelos alunos, tendo maior importância a quantidade, em detrimento à qualidade dos assuntos entendidos. A ênfase na execução de provas escritas (objetivas ou subjetivas) como principal meio avaliativo, calculado por notas, ainda é praticado na sociedade em defesa da aquisição do patrimônio cultural (GURGEL; LEITE, 2007; ANDRADE et al, 2018).

Vale ressaltar que alunos da área da saúde apontam como aspecto limitador a oferta mínima de aulas práticas preconizadas pelas Resoluções Nacionais que instituem as Diretrizes Curriculares dos Cursos. As aulas práticas convergem com a pedagogia histórico-crítica pelo propósito de oportunizar o exercício profissional de maneira dinâmica e diferenciada ao estimular melhor atitude e desempenho docente, melhor interação professor e aluno, processo avaliativo diferenciado por levar em consideração as peculiaridades do desempenho de cada aluno, além do desenvolvimento psíquico diante da atividade fictícia realizada (SILVA, 2014; QUEIROZ et al, 2020).

Desta forma, observam-se atividades docentes que se aproximam de práticas educativas emancipatórias como as insuficientes aulas práticas, embora com processos avaliativos concentrados na realização de provas, na opinião de estudantes da área da saúde e da educação, revelando opção por práticas educativas não emancipatórias.

\section{CONSIDERAÇÕES FINAIS}

Diante dos resultados expostos foi possível conhecer os aspectos potencializadores e limitadores das práticas educativas docentes ficando evidente a escolha por diversas estratégias pedagógicas em suas atividades laborais: estímulo no pensamento crítico e reflexivo, debates, seminários, mapas mentais, investigação, discussão de artigos científicos, exposição de vídeos, aulas práticas e utilização da prova como método avaliativo principal. 
Esse arsenal de práticas educativas ancora abordagens pedagógicas emancipatórias e não emancipatórias demonstrando avanço pedagógico diante da possibilidade de reconsiderar as ações docentes em vistas à superação de metodologias tradicionais por meio da operacionalização dos pressupostos da Resolução Nacional que institui as Diretrizes Curriculares, como as aulas práticas.

Embora seja realizada em uma Instituição Federal de Ensino Superior de um pequeno município paraibano, este estudo poderá levar à reflexão a necessidade de atualização da Matriz Curricular dos Cursos de Bacharelado, atendendo aos anseios modernos por práticas educativas emancipatórias, podendo subsidiar futuras pesquisas docentes no tocante ao aprofundamento teórico da formação acadêmica, em nível de graduação/bacharelado, dos cursos das áreas de educação e saúde.

O aprofundamento da temática, embora limitada ao espaço micropolítico do desenvolvimento de um Centro Universitário, poderá contribuir de forma efetiva para reflexões frutíferas envolvendo estratégias emancipatórias voltadas à formação do enfermeiro.

\section{REFERÊNCIAS}

ERDMANN, A.L.; SANTOS, J.L.G.; KLOCK, P.; SODER, R.M.; SASSO, G.T.M.D.; ERDMANN, R.H. Políticas, gerência e inovação de grupos de pesquisa para a excelência em enfermagem. Aquichan, Chía, Colombia, 2013. v. 13, n. 1, p. 92-103. Disponível em: <https://docs.bvsalud.org/biblioref/2020/09/49939/2346-14467-1-pb.pdf> Acesso em: 09 mai 2018.

FIOCHI, P.I.C.Q. (2016). Uma reflexão sobre a pesquisa e a produção de conhecimento na universidade. Revista de Psicologia da UNESP, 15(1), 17-25. Disponível em: $<$ http://pepsic.bvsalud.org/scielo.php?script=sci_arttext\&pid=S198490442016000100002\&lng=pt\&tlng=pt>. Acesso em: 15 Jun 2021.

FARIAS, L.D.; SILVA, C.C. Administração em enfermagem: desvelando as bases conceituais, metodológicas e pedagógicas de seu ensino em João Pessoa-PB. Cienc. Cuid Saúde, 2008. v. 7, n. 1, p. 37-44. Disponível em:

$<$ http://www.ccs.ufpb.br/ppgeold/dissertacoes2007/dissertacaolucianadantas.pdf $>$. Acesso em: 15 Jun 2021.

LIBANEO, J.C. Democratização da Escola Pública: a pedagogia crítico - social dos conteúdos. 20. ed. São Paulo: Loyola, 2005. Acesso em: 15 Jun 2021. 
MINAYO MCS. O Desafio do conhecimento: pesquisa qualitativa em saúde. 10. ed. São Paulo: Hucitec/Abrasco, 2007. 406 p. Acesso em: 15 Jun 2021.

COSTA, C.; LOUREIRO, C. (2019). Interdisciplinaridade, Materialismo Histórico-Dialético e Paradigma da Complexidade: Articulações em Torno da Pesquisa em Educação Ambiental Crítica. Pesquisa em Educação Ambiental. 14. DOI: https://doi.org/10.18675/2177580X.vol14.n1.p32-47. Acesso em: 15 Jun 2021.

BRASIL. Ministério da Saúde. Resolução 466/12 do Conselho Nacional de Saúde/MS: Diretrizes e Normas Regulamentadoras de Pesquisa envolvendo seres humanos. Diário Oficial da União, 13 de junho de 2013. Disponível em: http://conselho.saude.gov.br/resolucoes/2012/reso466.pdf. Acesso em: 09 mai 2018.

FONTANELLA, B.J.B.; LUCHESI, B.M.; SAIDEL, M.G.B. RICAS, J.; TURATO, E.R.; MELO, D,G. Amostragem em pesquisas qualitativas: Proposta de procedimentos para constatar saturação teórica. Cad. Saúde pública, Rio de Janeiro, 2011. v.27, n.2, p.389-394. Disponível em: https://www.scielosp.org/article/csp/2011.v27n2/388-394/. Acesso em: 09 mai 2018.

SILVA, L.; RUSSO, R. (2019). Aplicação de entrevistas em pesquisa qualitativa. Revista de Gestão e Projetos, 10(1), 1-6. DOI: https://doi.org/10.5585/gep.v10i1.13285. Acesso em: 15 Jun 2021.

TRIVIÑOS, A.N.S. Bases teórico-metodológicas da pesquisa qualitativa em ciências sociais. Caderno de Pesquisa, 2001. v. 4, n.1, p. 73-106. Acesso em: 09 mai 2018.

FIORIN, J.L. Elementos de análise do discurso. São Paulo: Contexto 2005. Acesso em: 09 mai 2018.

VIEIRA, S.L.; SILVA, G.T.R.; SILVA, R.M.O.; AMESTOY, S.C. Diálogo E Ensino-Aprendizagem Na Formação Técnica Em Saúde. Trab. educ. saúde, Rio de Janeiro, 2020. v.18, supl. 1, e0025385. DOI: https://doi.org/10.1590/1981-7746-sol00253. Acesso em: 15 Jun 2021.

RUIZ-MORENO, L. PITTAMIGLIO, S.E.L.; FURUSATO, M.A. Lista de discussão como estratégia de ensino-aprendizagem na pós-graduação em Saúde. Interface (Botucatu), Botucatu, 2008. v.12, n.27, p.883-892. DOI: https://doi.org/10.1590/S1414-32832008000400017. Acesso em: 24 Set 2020.

ANDRADE, L.D.F.; GERMANO, H.S.; PINTO, M.B.; OLIVEIRA, L.C.S.; MEDEIROS, H.A.; LIMA, E.A.R. (2018). Práticas educativas que ancoram a formação de recursos humanos em um curso de bacharelado em enfermagem. Revista de Enfermagem e Atenção à Saúde, [Online]. Jan/Jul 2018, v.7, n.1, p. 89-101. DOI: https://doi.org/10.18554/reas.v7i1.1989. Acesso em: 15 Jun 2021.

GURGEL, C.R.; LEITE, R.H. Avaliar aprendizagem: uma questão de formação docente. Ensaio: Avaliação e Políticas Públicas em Educação [online], Rio de Janeiro. 2007, v.15, n.54, p. 145168. DOI: https://doi.org/10.1590/S0104-40362007000100009. Acesso em: 24 Set 2020. 
SILVA, V.C.; VIANA, L.O.; SANTOS, C.R.G.C. Prática social e pedagógica do enfermeiropreceptor: um estudo de caso. Online Braz J Nurs [online]. 2014; 13(1):102-12. Disponível em: <http://www.revenf.bvs.br/pdf/objn/v13n1/v13n1a12.pdf>. Acesso em: 15 Jun 2021.

QUEIROZ, A.C.; DANTAS, M.C.S.; QUEIROZ, A.M.; ANDRADE, L.D.F. Concepção de discentes acerca das práticas educativas que ancoram a disciplina gestão em enfermagem ii. SALUSVITA, Bauru, v. 39, n. 3, p. 671-682, 2020. Disponivel em: <https://secure.unisagrado.edu.br/static/biblioteca/salusvita/salusvita v39 n3 2020/salusv ita v39 n3 2020 art 04.pdf>. Acesso em: 15 Jun 2021. 